\title{
Determining Individual Phase Properties in a Multi- phase Q\&P Steel Using Multi-scale Indentation Tests
}

\author{
G. Cheng, K.S. Choi, X. Hu, X. Sun* \\ Pacific Northwest National Laboratory \\ P.O. Box 999, Richland, WA 99352, USA
}

\begin{abstract}
A new inverse method was developed to predict the stress-strain behaviors of constituent phases in a multi-phase steel using the load-depth curves measured in nanoindentation tests combined with microhardness measurements. A power law hardening response was assumed for each phase, and an empirical relationship between hardness and yield strength was assumed. Adjustment was made to eliminate the indentation size effect and indenter bluntness effect. With the newly developed inverse method and statistical analysis of the hardness histogram for each phase, the average stress-strain curves of individual phases in a quench and partitioning (Q\&P) steel, including austenite, tempered martensite and untempered martensite, were calculated and the results were compared with the phase properties obtained by in-situ high energy X-ray diffraction (HEXRD) test. It is demonstrated that multi-scale instrumented indentation tests together with the new inverse method are capable of determining the individual phase flow properties in multi-phase alloys.
\end{abstract}

Key words: Nanoindentation; Multi-phase; Plastic flow properties; Microstructure

\footnotetext{
* Corresponding author. Tel.: +1 509372 6489; fax: +1 5093752604

E-mail address: xin.sun@pnnl.gov (X.Sun)
} 


\section{Introduction}

Indentation hardness test is a widely used characterization technique in interrogating material's properties at different scales. Microindentation test is a mature technology that has been used by material scientists for almost a century in quantifying microhardness of materials with different structures $[1,2]$. Typically, a diamond indenter of a specific geometry is impressed into the surface of a test specimen using a known applied force, and the produced indentation depth ranges from 1 to 50 micron. It is well known that the microhardness measurements vary with indenter geometry, indentation depth and work hardening effects of materials. In addition, the early versions of the microindentation tests typically did not record the load-depth curves during the tests. Later, with the development of depth sensing technique, a load-depth curve could be measured during the indentation test as the schematics shown in Fig. 1. Instrumented indentation such as those described by ASTM standard E2546-07 developed based on the OliverPharr's analysis of load-depth curves [3, 4] has been utilized to calculate the elastic modulus from unloading stiffness ( $S$ in Fig. 1(b)) with the assumption that the unloading curve is mainly dominated by the elastic properties. It offers great advantages in terms of small scale and ease of operation, and has been widely used in studying the properties, such as elastic modulus and hardness, of bulk materials, thin films and islands [5-11].

In addition to hardness and elastic modulus, many researchers have been investigating the possibilities of estimating the flow stress of ductile metals with the microindentation load-depth curves. Many numerical inverse methods have been proposed to extract the elasto-plastic properties from the microindentation load-depth curves using different number of indenters [5-7, 12-32]). Typically, a set of closed-form dimensionless functions between the indentation 
parameters and the elasto-plastic properties of the indented materials are proposed from dimensional analysis of some simulation data. For example, in the method proposed by Dao et al. [12], with a single Berkovich indenter, elastic modulus, representative stress, hardening exponent and yield strength were calculated successively. Generally speaking, these methods rely on a large number of finite element simulations to include most possible engineering materials and are verified with load-depth (i.e., $10 \mu \mathrm{m}$ ) curves from microindentation experiments $[12,14,17$, 24]. At this indentation depth, the indentation size effect (ISE) [8, 33] and indenter bluntness effect [34] do not have significant influence on the load-depth curves.

On the other hand, more and more advanced multi-phase materials with small grain size and sub-micron microstructural features are developed for engineering applications. Several studies have demonstrated the applicability of nanoindentation in characterizing microstructures of fine grain multi-phase alloys, including $\mathrm{Ni}-\mathrm{Cu}$ coatings, magnesium alloys and dual-phase (DP) steels [20, 37-45]. For multi-phase materials with grain sizes less than $10 \mu \mathrm{m}$, the indentation depth needs to be less than $100 \mathrm{~nm}$ to ensure that indentations locate only within specific grains of interest [40-44]. In recent nanoindentation study of DP980 steels reported by Taylor et al. [42], the indentation depths were no more than $40 \mathrm{~nm}$ to accommodate the small grain size of each phase (around $2 \mu \mathrm{m}$ ).

Among the various advanced multi-phase alloys, quenching and partitioning (Q\&P) steels have attracted wide attentions due to its combination of high strength and good ductility. Usually, Q\&P steels have very complex microstructures constituted of a variety of different phases including retained austenite, tempered/untempered martensite and ferrite [46]. Individual phase constitutive properties (especially the flow behavior) are therefore crucial in determining the overall mechanical properties of the material, including tensile strength, ductility, and 
formability [47, 48]. On the characterization side, even though there have been many nanoindentation studies on multi-phase alloys [20, 37-45], most of them measured and made direct use of the nanohardness $[38,43]$, and few attempted to calculate the entire flow behavior of individual phases including yield strength and hardening exponent [20]. In multi-phase materials with small grains, three challenges exist in extracting the flow behaviors of individual phases:

(1) The small grains size (usually less than $3 \mu \mathrm{m}$ ) and complex microstructures [49] make it difficult to identify each phase/grain within a polished unetched sample. Even though it is theoretically possible to get unique solutions by making indentations with multiple indenters on a multi-phase steel with relatively large grains [20], it is physically impractical to fit multiple indentations within a single grain of a Q\&P steel [49] with the average grain sizes of 1-2 $\mu \mathrm{m}$.

(2) Most inverse methods are developed for indentation tests at the micro-level where ISE and indenter bluntness effect have much less influence on the load-depth curves. However, shallow indentation depth (around $50 \mathrm{~nm}$ ) is required for Q\&P steels to locate the indentation within a specific grain in order to avoid plastic interference, which mandates that ISE and indenter bluntness effect be taken into consideration before the application of inverse calculation with the load-depth curves measured from nanoindentation.

(3) Inverse methods based on single indenter Berkovich test have the difficulty of nonunique solutions due to insufficient independent variables available in solving a multiplevariable problem [50]. To avoid this problem, one possible solution is to determine the variables one at a time, by other relationships [51, 52]. 
Note that, besides indentation, micro/nanopillar compression and high energy X-ray diffraction (HEXRD) have also been explored in direct and indirect measurements of the constituent phase properties in these multi-phase steels. Hosemann et al. [38], Ghassemi-Armaki et al. [43] and Stewart et al. [53] reported the application of micro/nanopillar compression test as a direct measurement in determining the single crystal-level critical resolved shear stresses for different steels. However, the complex and sub-micron features in the current Q\&P sample render it extremely difficult to prepare samples of single grain/phase for micro/nanopillar testing. Recently, HEXRD has also been explored to investigate individual phase properties with different assumptions and self-consistent approximations as an indirect method to obtain phase properties [54]. In addition to the uncertainties introduced by the various inverse calculations, limited access to a specialized high energy X-ray facility also limits the widespread use of such a method. Overall speaking, even though the materials research community has been actively investigating individual phase properties of various multi-phase alloys in recent years, no single technique has been widely accepted as a standard method as of today.

The objective of this study is to determine the average phase stress-strain behaviors in a multi-phase Q\&P steel with nanoindentation load-depth curves, and it was accomplished by extending the previously reported micro-indentation methods into the nano-indentation regime by considering the ISE and indenter bluntness effect. The estimated phase properties are compared and contrasted with those determined independently with in-situ HEXRD [54], and the applicability and advantages of nanoindentation in extracting phase properties in a multi-phase material with small grains are further discussed. 


\section{Experiment}

The material in this study is a low alloy $(0.2 \mathrm{C}-3 \mathrm{Mn}-1.6 \mathrm{Si}$, in wt $\%) \mathrm{Q} \& \mathrm{P}$ steel with specific thermomechanical processing parameters aimed at creating sub-micron microstructure and stability features to achieve desired engineering properties [49]. SEM (JEOL, 7000F fieldemission SEM, Japan) with an electron backscatter diffraction (EBSD) detector allowing crystallographic analysis is utilized to characterize the microstructures of the Q\&P steel. Fig. 2(a) shows a SEM micrograph obtained from the in-plane cross-section (RDxTD, where RD stands for the rolling direction and TD for transverse direction). As shown in Fig. 2(a), the Q\&P steel contains multiple refined microstructural constituents with sizes less than $2 \mu \mathrm{m}$, which are much smaller than the grain size of the dual phase steel studied by multi-indenter method [20]. Since nanohardness has been successfully used in studying the deformation characteristics of various DP980 steels with comparable grain size [42], small indentation depth should also be applicable in the current Q\&P samples.

Considering that the nanoindentation responses of various grains belonging to the same phase could be different due to differences in grain size, elemental distribution and grain orientation, a 20 by 20 indentation array was performed on the Q\&P sample to ensure that sufficient indents for each phase are used in obtaining the average phase stress-strain response. Nanoindentation tests were then performed using a Hysitrons TI 950 Triboindenter (US) on unetched surface. The sample was prepared using standard techniques and polished to a $1 \mu \mathrm{m}$ diamond finish with the addition of a final $0.05 \mu \mathrm{m}$ colloidal silica vibratory polishing step. The resulting sample roughness was $4 \sim 10 \mathrm{~nm}$. All nanoindentation tests were performed using a Berkovich indenter tip operated in displacement-control mode to a depth of $30 \mathrm{~nm}$ at the rate of $10 \mathrm{~nm} / \mathrm{s}$ for both loading and unloading, and the load-depth curves for all the indentations were 
recorded. An indentation spacing of $2 \mu \mathrm{m}$ was chosen to eliminate potential effects of overlapping plastic zones [36]. After indentation, the tested area was imaged using SEM and a transparent film was placed on the SEM image to record the location of each indentation. The sample was then etched with $2 \%$ nital to reveal the microstructure, and placed back in the SEM. The same area was imaged at the same magnification as the polished surface with the indentations. Since most indentations were not visible after etching, the transparent film was placed over the etched SEM micrograph to locate the indentations, using visible indents for alignment [42]. Fig. 3 shows the resulting final image used to identify the indentation locations. In addition to the nanoindentation tests as described above, microindentation test was also performed on the Q\&P sample to an indentation depth of $2 \mu \mathrm{m}$ in order to measure the microhardness based on the combined response of the constituent phases.

In-situ HEXRD test under uniaxial tensile loading conditions was performed with the Q\&P steel at Advanced Photon Source to determine the mechanical properties of the constituent phases as well as to obtain the austenite volume fraction evolution during the deformation process. Through the detailed data analysis of the diffraction pattern during tensile loading, the lattice strains of various crystal planes were first calculated as a function of the macroscopic strain. The phase properties of the constituent phases were estimated by elasto-plastic selfconsistent crystal plasticity modeling, and used in this study to validate and verify the phase properties extracted from nanoindentation tests. Hu et al. [54] can be referred to for the details on the determination of phase properties of the multi-phase Q\&P steels with in-situ HEXRD. 


\section{Extraction of stress-strain curves from multi-scale indentation tests}

In this section, the detailed procedures of the new method will be presented in extracting stress-strain curves from multi-scale indentation tests. For the completeness of this paper and the definition of analysis symbols, some brief reviews of the previously developed indentation methodology are also included to justify the improvements made in this study.

Fig. 1 shows the typical indentation set up and load-depth $(P-h)$ curve obtained from instrumented indentation test. In general, the loading response can be described by Kick's law [12]:

$$
P=C h^{2}
$$

where $C$ is the loading curvature. In the curve shown in Fig. 1(b), $P_{\max }$ and $h_{\max }$ are the maximum indentation load and depth, respectively, and $h_{r}$ is the residual depth after complete unloading. $h_{c}$ is the effective indentation depth which is defined as

$$
h_{c}=h_{\max }-\epsilon \frac{P_{\max }}{S}
$$

where $S$ is measured stiffness of the upper portion of the unloading data and $\epsilon$ is a constant depending on the indenter geometry, with the value of 0.75 for the Berkovich indenter adopted here [3].

Most metallic materials' plastic behaviors can be closely approximated by a power law. Fig. 1(c) shows a schematic stress-strain $(\sigma-\varepsilon)$ curve and material's elasto-plastic behavior can be described as [12]

$$
\begin{cases}\sigma=E \varepsilon & \text { for } \sigma \leq \sigma_{y} \\ \sigma=\sigma_{y}\left(1+\frac{E}{\sigma_{y}} \varepsilon_{p}\right)^{n} & \text { for } \sigma \geq \sigma_{y}\end{cases}
$$


where $E$ is the elastic modulus, $\sigma_{y}$ is the yield strength and $n$ is the hardening exponent. $\varepsilon_{p}$ is the nonlinear part of the total strain $\varepsilon$, accumulated beyond the yield strain $\varepsilon_{y}$, and defined as

$$
\varepsilon_{p}=\varepsilon-\varepsilon_{y}
$$

With the assumed power law in Eq. (3), the values $E, \sigma_{y}$ and $n$ determine the material's overall stress-strain behavior.

Since very small indentation depth was adopted in the current study, i.e., $30 \mathrm{~nm}$, to accommodate the small grain size of the Q\&P steel, a new inverse method is proposed which enables the extraction of individual phase stress-strain curves from the nanoindentation loaddepth curves: the elastic modulus and hardness are calculated by the Oliver-Pharr method [3, 4]; to ensure solution uniqueness, the empirical relationship between nanohardness and yield strength reported by Rodríguez and Gutierrez [51] was introduced to calculate yield strength, which leaves hardening exponent the only variable left to be determined; a correlation factor considering the ISE and indenter bluntness effect is proposed to convert the loading curvatures from nanoindentation to microindentation in order to calculate the representative stress [12]; finally, the hardening exponent is calculated from yield strength and representative stress. Fig. 4 summarizes the flow chart of the proposed inverse method consisting of four steps, and detailed explanations of each step are described below.

\subsection{Determination of hardness $H$ and elastic modulus $E$}

The hardness $H$ and elastic modulus $E$ are determined by the method proposed by OliverPharr $[3,4]$. Prior to the nanoindentation test on the Q\&P sample, the contact area function was measured by an indirect method, where 49 indentations were performed on quartz with the indentation depth ranging from $0-100 \mathrm{~nm}$ [56]. The measured contact area function $A_{c}$ is expressed as 


$$
A_{c}=\theta_{0} h_{c}^{2}+\theta_{1} h_{c}+\theta_{2} h^{\frac{1}{2}}+\theta_{3} h_{c}^{\frac{1}{4}}+\theta_{4} h_{c}^{\frac{1}{8}}+\theta_{5} h_{c}^{\frac{1}{16}}
$$

where $\theta_{0}=24.5, \theta_{1}=3042, \theta_{2}=-197210, \theta_{3}=2126800, \theta_{4}=-5537200$ and $\theta_{5}=3638100$. With the maximum indentation depth $h_{\max }$ of $30 \mathrm{~nm}$ in this study, the average effective indentation depth $h_{c}$ is approximately $27 \mathrm{~nm}$. The contact area at this indentation depth is calculated to be $33514 \mathrm{~nm}^{2}$ with Eq. (5). This contact area is nearly twice the calculated result with the first term of Eq. (5): $A_{c}=24.5 h_{c}{ }^{2}=17861 \mathrm{~nm}^{2}$, which is the nominal area function for a perfect Berkovich indenter without consideration of any bluntness effect or non-ideal geometry for microindentation $[36,56]$. This indicates that significant indenter bluntness effect exists at the shallow indentation depth.

The hardness for the nanoindentation is calculated using Eq. (6) [3]:

$$
H=\frac{P_{\max }}{A_{c}}
$$

Then, the reduced modulus, $E_{r}$, as well as the elastic modulus, $E$, of the Q\&P sample are calculated using Eqs. (7) and (8) [3]:

$$
\begin{gathered}
E_{r}=\frac{\sqrt{\pi} S}{2 \sqrt{A_{c}}} \\
\frac{1}{E_{\mathrm{r}}}=\frac{1-v^{2}}{E}+\frac{1-v_{i}^{2}}{E_{i}}
\end{gathered}
$$

where $E_{i}=1140 \mathrm{GPa}$ and $v_{i}=0.07$ are the elastic modulus and Poisson's ratio, respectively, adopted for the diamond indenter in this study. The elastic modulus, $E$, can be determined if the Poisson's ratio for the Q\&P steel is assume to be $v=0.3$.

\subsection{Determination of yield strength $\sigma_{y}$}

Rodríguez and Gutierrez [51] studied the correlation between yield strength $\left(\sigma_{y}\right)$ and hardness $(H)$ of different single phase metals by performing nanoindentation tests with 
indentation depth ranging from 50 to $2000 \mathrm{~nm}$. They reported a general linear relationship between the yield strength and the nanohardness values measured with a Berkovich indenter in the form of

$$
H=a \sigma_{y}+b
$$

where both $\sigma_{y}$ and $H$ are in the units of GPa. However, the values of $a$ and $b$ depend on the indentation depth, and the authors attributed these to the well-known "indentation size effect". A recent study by Hackney et al. [57] shows that the nanohardness values measured at various locations in a Q\&P steel are quite consistent at the indentation depth ranging from 30 to $50 \mathrm{~nm}$. Hence the experimental data reported by Rodríguez and Gutierrez [51] at $50 \mathrm{~nm}$ are used to correlate yield strength and nanohardness for the indentation depth of $30 \mathrm{~nm}$ adopted in this study, which yields: $a=5.2$ and $b=1.3 \mathrm{GPa}$.

\subsection{Determination of representative stress $\sigma_{r}$}

In the inverse method proposed by Dao et al. [12], a representative stress $\sigma_{0.033}$ at $\varepsilon_{p}=0.033$ is identified such that the following relationship holds independent of the hardening exponent $n$ :

$$
\frac{C}{\sigma_{0.033}}=-1.131\left[\ln \left(\frac{E_{r}}{\sigma_{0.033}}\right)\right]^{3}+13.635\left[\ln \left(\frac{E_{r}}{\sigma_{0.033}}\right)\right]^{2}-30.594\left[\ln \left(\frac{E_{r}}{\sigma_{0.033}}\right)\right]+29.467
$$

where $C$ is the loading curvature and $E_{r}$ is the reduced modulus introduced earlier. However, the inverse method proposed by Dao et al. [12] assumes a perfect Berkovich indenter tip with the indentation behavior following Eq. (2) without considering ISE. Hence the value of $C$ obtained from experimental fitting of Eq. (1) cannot be directly used in estimating the representative stress in Eq. (10) since both ISE and indenter bluntness effect have to be taken into consideration.

In order to consider the ISE at shallow indentation depth, a modified loading response described by Eq. (11) was employed by Hosemann et al. [38] and Bucaille et al. [55]: 


$$
\mathrm{P}=C_{n} h^{2} \sqrt{1+\frac{h^{*}}{h}}
$$

where $C_{n}$ is the modified loading curvature considering ISE and $h^{*}$ is the characteristic length that depends on the shape of indenter and the material. Note that $h^{*}$ is not a constant for a given material and indenter geometry, and it depends on the statistically stored dislocation density [8]. For example, Rodríguez and Gutierrez [51] calculated $h^{*}$ could range from $210 \mathrm{~nm}$ to $270 \mathrm{~nm}$ for different martensite steels through a diamond Berkovich indenter test from $50 \mathrm{~nm}$ to $3000 \mathrm{~nm}$. Since martensite is the primary phase in the Q\&P steel and the ISE of each phase in the current Q\&P steel are difficult to measure given the complex microstructures as shown in Fig. 2, an averaged value of $h^{*}=240 \mathrm{~nm}$ from Rodríguez and Gutierrez [51] is adopted here. Note that the nanoindentation depth in this study is very shallow for a typical ISE model. In the Nix-Gao model, the hardness data for indentation less than about $0.1 \mu \mathrm{m}$ have been excluded because the shape of the indenter is not self-similar at small indentation depths due to the uncertainties in the contact area arose at small depths of indentation. To consider the effects of imperfect indenter tip geometry as well as the deviation of the initial loading curves from the ideal one due to initial elastic response $[41,58]$, only the portions of the experimental loading curves corresponding to the displacement from $10 \mathrm{~nm}$ to $30 \mathrm{~nm}$ are used in determining $C_{n}$ by fitting Eq. (11).

The loading curvature $C_{n}$ obtained above still cannot directly be used in Eq. (10) since the value of $\sigma_{0.033}$ in Dao's formulation is developed for microindentation only. In order to obtain the effective $C$ to be used in Eq. (10), a correction factor $\alpha$ is proposed in the present study to correlate the $C_{n}$ from nanoindentation (30nm) to an effective $C$ from microindentation:

$$
\alpha \equiv \frac{\bar{C}}{\overline{C_{n}}}
$$


where $\alpha$ can be obtained through the definitions of average nano- and micro-hardness through Eq. (6):

$$
\frac{\overline{H^{n}}}{\overline{H^{m}}}=\frac{\frac{\overline{P_{\max }^{n}}}{\overline{A_{c}^{n}}}}{\frac{\overline{P_{\max }^{m}}}{\overline{A_{c}^{m}}}}=\frac{\overline{C_{n}}\left(\overline{h_{\max }^{n}}\right)^{2} \sqrt{1+\frac{h^{*}}{\overline{h_{\max }^{n}}}}}{\frac{24.5{\overline{h_{\mathrm{c}}^{n}}}^{2}+3042 \overline{h_{\mathrm{c}}^{n}} \cdots \cdot}{24.5{\overline{h_{\mathrm{c}}^{m}}}^{2}}}
$$

In Eq. (12), $\overline{H^{x}}, \overline{P_{\text {max }}^{x}}, \overline{A_{c}^{x}}, \overline{h_{\mathrm{c}}^{x}}$ and $\overline{h_{\text {max }}^{x}}$ (superscript $m$ or $n$ ) are average hardness, average maximum indentation load, contact area, average effective indentation depth and maximum indentation depth from micro $(m)$ or nano $(n)$ indentation, respectively. Rearranging Eq. (12), the correction factor $\alpha$ can therefore be obtained as:

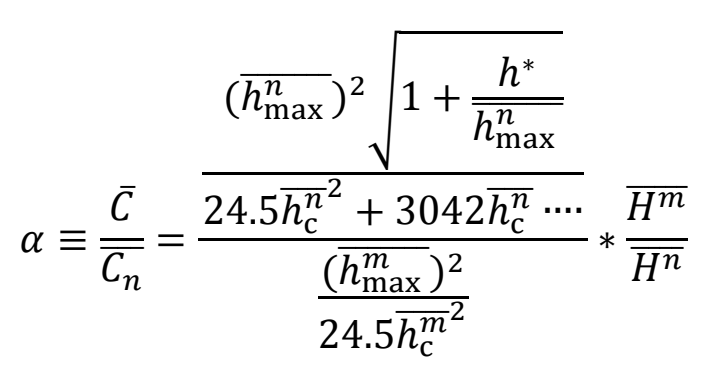

Here, the average microhardness measured from microindentation tests, $\overline{H^{m}}$ is $4.9 \mathrm{GPa}$ and the average nanohardness from 400 indentations, $\overline{H^{n}}$ is $6.25 \mathrm{GPa} . \overline{h_{\max }^{n}}$ and $\overline{h_{\mathrm{c}}^{n}}$ are $30.76 \mathrm{~nm}$ and $26.75 \mathrm{~nm}$, respectively; while $\overline{h_{\max }^{m}}$ and $\overline{h_{\mathrm{c}}^{m}}$ are $2.06 \mu \mathrm{m}$ and $1.84 \mu \mathrm{m}$, respectively. Previous studies $[59,60]$ reported that the ratios of $\left(\overline{h_{\max }^{n}} / \overline{h_{\mathrm{c}}^{n}}\right)$ and $\left(\overline{h_{\max }^{m}} / \overline{h_{\mathrm{c}}^{m}}\right)$ should be similar with increasing indentation depth or load for a stainless steel, i.e., $\left(\overline{h_{\max }^{n}} / \overline{h_{c}^{n}}\right)=1.19$ for $P_{\max }=$ $0.2 \mathrm{mN}$, and $\left(\overline{h_{\max }^{m}} / \overline{h_{\mathrm{c}}^{m}}\right)=1.16$ for $P_{\max }=200 \mathrm{mN}$. The results of our current study also confirms this observation: $\left(\overline{h_{\max }^{n}} / \overline{h_{c}^{n}}\right)=1.15$ for $P_{\max }=0.21 \mathrm{mN}$, and $\left(\overline{h_{\max }^{m}} / \overline{h_{\mathrm{c}}^{m}}\right)=1.12$ for $P_{\max }=375 \mathrm{mN}$. With these values, $\alpha$ is calculated to be 1.34 with Eq. (13). $\alpha$ is used as the correction factor to determine the $\bar{C}$ corresponding to $\overline{C_{n}}$ obtained from each load-depth curve 
from nanoindentation tests. After $\bar{C}$ is determined, Eq. (10) can be used to calculate the representative stress for each indentation with Dao's method.

\subsection{Determination of hardening exponent $n$}

Once the parameters $E, \sigma_{y}$ and $\sigma_{0.033}$ are determined, the hardening exponent $n$ for each indentation can be directly calculated by substituting $\sigma_{0.033}$ in Eq. (3):

$$
\sigma_{0.033}=\sigma_{y}\left(1+\frac{E}{\sigma_{y}} * 0.033\right)^{n}
$$

The material's stress-strain behavior is now fully described by Eq. (3) with the parameters $E, \sigma_{y}$ and $n$ determined. The examples of results obtained based on the above proposed inverse method are presented in Fig. 5. Fig. 5(a) shows two load-depth curves obtained from the nanoindentation tests of the Q\&P sample and their locations are marked in Fig. 3. As mentioned above, the initial portions of the loading curves which deviate from the rest of the loading curves due to indenter imperfection are not used in the inverse method proposed here, and Fig. 5 (b) shows the two corresponding stress-strain curves determined by the proposed method above with the determined material parameters listed.

To summarize, the proposed inverse method as shown in Fig. 4 enables the determination of a unique stress versus strain curve for a given nanoindentation load-depth curve. Hence the average phase properties of a multiphase material can be obtained by averaging the multiple stress strain curves obtained from the corresponding nanoindentation load-depth curves. 


\section{Determination of individual phase properties in a Q\&P steel}

\subsection{Microstructures of the $Q \& P$ steel}

The constituent phases in the Q\&P steel include austenite, tempered martensite and untempered martensite formed on cooling from the partitioning temperature. In Fig. 2(a), the "unraised" features (identified by dotted box, TM) are interpreted to be tempered martensite. Amongst the "raised" features, the thin needle-like grains (identified by arrow, A) are interpreted to be austenite, and the larger constituents (identified by solid box, A/UT) are interpreted to be austenite (A), untempered martensite (UT) or a mixture of both. The substantial fraction of tempered martensite is observed to have needle-like austenite grains in it (identified by dashed box, A/TM). In Fig. 2(b), raw phase image showed the geometry shape of austenite, and the volume fraction of austenite in the current Q\&P sample was calculated as $12.8 \%$ based on this phase map.

\subsection{Nanoindentation test results for each region}

Each indentation in Fig. 3 was categorized as located in tempered martensite region (i.e., TM), mixture of austenite and untempered martensite region (i.e., A/UT) or tempered martensite including thin austenite grains region (i.e., A/TM). Due to the small austenite grain size and the short distance between the grains compared to the indent size, the indentation within the A/TM could not be separately categorized into austenite or tempered martensite. Fig. 6 shows the histograms of nanohardness values obtained for the Q\&P steel, with the hardness distributions for TM in Fig. 6(a), A/TM in Fig. 6(b) and A/UT in Fig. 6(c). It is found that out of the 400 total indents: 112 located on TM, 202 on A/TM and 86 on A/UT. The wide range of hardness values for each constituent region observed in Fig. 6 reflects the effects of grain boundaries, different 
grain orientations, non-uniform chemical distributions and dislocation density within grains, as well as the potentially different microstructural features beneath the indented locations [42].

Generally, retained austenite has high thermal and mechanical stability with small grain size or high alloy elements (i.e., carbon or manganese) content [41,61, 62]. Since neither a rapid slope change in the loading curves nor a pop-out elbow in the unloading curves was observed from the indentation load-depth curves, it is deduced that deformation induced martensite transformation has not been triggered during the nanoindentation process [41, 63]. Thus, martensitic phase transformation is not considered in the current study. The material underneath the indenter experiences compressive stress during the indentation test, under which higher plastic strain is required for martensitic phase transformation than those in tensile test [64].

To calculate the properties of each phase, the indentations in each region should be categorized into individual phases. As observed in SEM in Fig. 2(a), the grain size of TM is generally larger than the indentation size. Therefore, the hardness data for TM shown in Fig. 6(a) can be considered to be solely from TM "grains". Meanwhile, the austenite and tempered martensite within the A/TM have needle-like microstructures and the grain size in this region is much smaller compared to the indentation size, and it is impossible to separate indentation data for each constituent grain in the A/TM. Hence, the hardness data shown in Fig. 6(b) represents the combined hardness from austenite and tempered martensite in the A/TM.

Although the grain size of A/UT is relatively large compared to the indentation size, the actual phase (i.e., austenite or untempered martensite) at the indentation location within the A/UT grains could not be identified from the simple observation of the SEM image. Since the hardness histogram of A/UT approximates a bimodal distribution as schematically illustrated by the blue curve in Fig. 6(c), bimodal Gaussian fit is utilized to estimate the area for each peak. 
Given that austenite is generally softer than untempered martensite, the red and green curves represent possible normal hardness distributions of austenite and untempered martensite, respectively. With these fittings, it is reasonable to assume that, among all the data for A/UT, the indentations with hardness lower than $6 \mathrm{GPa}$ belong to austenite, whereas the indentations with hardness higher than $6 \mathrm{GPa}$ belong to untempered martensite. Subsequently, 25 and 61 indents are counted as austenite and untempered martensite, respectively. Retrospectively, it would have been straightforward to verify the above assumption by overlaying the nanoindentation map with the corresponding EBSD raw image. However, this correlation was not carried out in the present study, and future verification work should be planned to assess the accuracy of this hardnessbased phase separation.

Table 1 lists the phase volume fractions (PVF) measured from HEXRD test as well as those estimated from the nanoindentation tests. Here, the PVF from nanoindentation are defined by the number of indentations located on a specific phase divided by the total number of indentations (i.e., 400). The volume fraction of austenite measured from EBSD is $12.8 \%$ and this value is also confirmed by HEXRD. Assuming that the total austenite PVF estimated from nanoindentation tests should be approximately $13 \%$, the number of indents, 202 , on A/TM is intentionally divided into two parts: 27 for austenite and 175 for tempered martensite. When this division is made for the indents on $\mathrm{A} / \mathrm{TM}$, the PVF of tempered martensite and untempered martensite estimated from the nanoindentation tests are found to be similar to those measured from HEXRD as listed in the Table 1.

\subsection{Calculation of phase stress-strain curves}

With the inverse method described in the previous sections, the elastic modulus, yield strength and hardening exponent are calculated for all the load-depth curves obtained from the 
nanoindentation tests. The stress-strain curves are categorized into four different constituent regions (i.e., TM, A, UT and A/TM) as shown in Fig. 7 and then used to calculate the average stress-strain curve for each phase. Here, among the indentation data for A/UT shown in Fig. 6(c), the data with hardness value higher than $6 \mathrm{GPa}$ (i.e., 61 indents) were used to obtain the untempered martensite phase properties, and the rest (i.e., 25 indents) were used to obtain the austenite phase properties. Also, the hardness data from A/TM are assumed to reflect the combined behavior of the two phases. Hence, the curve shown in Fig. 7(d) only represents an average stress-strain curve for the A/TM, which is not the single phase property for austenite or tempered martensite.

The average flow stress of untempered martensite is readily available as shown in Fig. 7(c) among the three distinct constituent phases. However, austenite should include austenite identified from A/UT and A/TM, while tempered martensite should include the contributions from both the single phase TM and the mixed region in A/TM. Based on SEM observations in Fig. 3, A/TM is the main feature in Q\&P steels which accounts for 202 out of the overall 400 indents, and therefore the contribution from A/TM cannot be overlooked. Generally speaking, hardness values for austenite and tempered martensite depend on their respective carbon contents and dislocation densities, and they can be significantly different for on chemical compositions and the corresponding thermomechanical processing parameters [45]. In the current Q\&P steel, the average hardness of austenite in A/UT (5.50 GPa from Fig. 6(c)) is very close to the average hardness of TM (5.82 GPa from Fig. 6(a)). In addition, the austenite lath is much thinner than the tempered martensite in the A/TM region, making it impossible to separate austenite from tempered martensite. With the above considerations, austenite and tempered martensite in the current Q\&P steel are assumed to have the same hardness distributions but with different 
frequencies in A/TM as depicted in Fig. 6(b). The following weighted average is therefore proposed to calculate average flow stress of austenite:

$$
\sigma_{a}=\frac{25 * \overline{\sigma_{A(A / U T)}}+27 * \overline{\sigma_{A / T M}}}{52}
$$

where $\overline{\sigma_{A(A / U T)}}$ and $\overline{\sigma_{A / T M}}$ are the average flow stress of 'austenite from A/UT' and 'A/TM' respectively, as shown in the red and black curves in Fig. 8(a). The flow stress of austenite thus calculated is plotted as the blue curve in Fig. 8(a).

Similar to austenite, tempered martensite should also include contributions of indentations from two regions: TM and A/TM. The flow stress of tempered martensite is calculated through the weighted average:

$$
\sigma_{t m}=\frac{112 * \overline{\sigma_{T M}}+175 * \overline{\sigma_{A / T M}}}{287}
$$

where $\overline{\sigma_{T M}}$ and $\overline{\sigma_{A / T M}}$ are the average flow stress of 'tempered martensite from TM' and 'A/TM', respectively, as shown in the red and black curves in Fig. 8(b). Hence, the flow stress of tempered martensite is calculated as the blue curve in Fig. 8(b). The average flow stress for untempered martensite determined in Fig. 7(c) is replotted alongside with those for austenite and tempered martensite in Fig. 8(c) as a comparison.

For verification purpose, Fig. 9(a) compares the phase stress-strain curves of the austenite (red), tempered martensite (black) and untempered martensite (blue) obtained in this study (dashed lines) with the HEXRD deduced curves (solid lines) for the same Q\&P steel. As shown in Fig. 9, the initial portions of the flow behaviors predicted by the two methods appear to be similar to each other, while the hardening exponents predicted by the two methods show some differences. The phase stress-strain curves for the austenite and tempered martensite derived from the indentation tests do not show as much differences in the flow behaviors as those derived 
from HEXRD test. Since the hardening exponent is the last parameter to be determined for each phase in the proposed method, uncertainties in the upstream yield strength and representative stress calculations can significantly influence the resulting hardening rate for each phase in the proposed inverse method. In determining yield strength for each phase as described earlier, an empirical fitting of experimental data reported by Rodríguez and Gutierrez [51] in the form of Eq. (9) was used with coefficients $a=5.2$ and $b=1.3 \mathrm{GPa}$ for all three phases. Since scatters in experimental data are also observed for different phases by Rodríguez and Gutierrez [51], different values of the coefficient $b$ are adopted next to examine the effects of the yield strength on the average phase stress-strain curves of the Q\&P steel. For this purpose, $b=0.8 \mathrm{GPa}$ (lower bound) and $b=1.8 \mathrm{GPa}$ (upper bound) are adopted for martensite and austenite, respectively. Fig. 9(b) compares the subsequently calculated phase stress-strain curves based on the new coefficient $b$ with those derived from HEXRD test. As shown in the Fig. 9(b), the phase stressstrain curves predicted from the two methods become quite similar to each other. Note that even though the HEXRD-based results are used here to cross compare with the nanoindentation predicted stress-strain curve, they are also derived from inverse calculations and subject to uncertainties. Hence, they should only be used as references rather than standards or baselines for this class of materials [54]. Overall similarities in the predicted flow properties for various phases in Fig. 9 confirm that the proposed nanoindentation-based inverse method can provide reasonably accurate individual phase flow property estimations for the multi-phase Q\&P steel with sub-micron grain features. 


\section{Discussions}

\subsection{Advantages and limitations of the proposed inverse method}

As discussed before, Dao et al. [12] developed a complete algorithm to calculate the properties from load-depth curves. With the original method, the hardening exponent could be overestimated due to inaccuracies introduced by the reduced modulus and/or the compliance of the indenter tip $[65,66]$. Furthermore, the solutions cannot avoid the non-uniqueness issue with the load-depth curve generated from single Berkovich indentation [5, 22, 30, 33]. To circumvent the above-mentioned problems, only part of the Dao's algorithm is used in the currently proposed inverse method to obtain representative stress (as Eq. (10)). To ensure uniqueness of the inverse algorithm, a power law type stress-strain relationship (as Eq. (3)) has been assumed for the various phases of the Q\&P steel and the relationship between presentative stress and loading curvature is fitted by dimensionless analysis proposed by Dao et al. [12]. In spite of the possible errors these assumptions may bring, they are necessary to make the inverse problem unique and deterministic.

It should be noted that an empirical relationship between yield strength and nanohardness experimentally determined by Rodríguez and Gutierrez [51] was utilized. With a modified yield strength-nanohardness relationship, it could be observed that the initial portions of the phase stress-strain curves obtained are quite similar to those determined by HEXRD (see Fig. 9). Since there are uncertainties in the experimental data, the choice of parameters for the empirical equation, such as $a$ and $b$ in Eq. (9), could significantly influence the hardening behavior of the stress-strain curves as the comparison shown in Fig. 9(a) and (b). Further work in the current inverse method should focus on developing a more accurate way in determining the yield strength of individual phase based on nanohardness. 
In addition, as rightfully reported by previous research, surface roughness would also influence the load-depth curves of nanoindentation tests [67-69]. In the current study, loading curves of most indentation come with fluctuations within 10-30 nm, as shown Fig. 5(a), and this could be caused by the surface roughness effects since the indentation depth is $30 \mathrm{~nm}$ and surface roughness is $4 \sim 10 \mathrm{~nm}$ after polishing. However, the observed fluctuations in the experimental load-depth curves as shown in Fig. 5 is not as significant as those reported in previous work [6769], which suggests that the influence of surface roughness would not be significant and hence can be ignored in the inverse methodology.

\subsection{Comparison with HEXRD and micro/nanopillar test}

Previous studies have successfully used in-situ HEXRD tests in obtaining the individual phase properties of multiphase steels [54]. HEXRD is a through-thickness volumetric measurement which yields the diffraction patterns of a rather large volume, e.g. a cylindrical volume with the beam diameter (around $0.5 \mathrm{~mm}$ ) through the entire sample thickness. Therefore, the average stress strain curves obtained based on HEXRD should be statistically representative. However, the HEXRD-based techniques require access to limited high energy light sources which could potentially limit their widespread use. In addition to light source access, it also requires post-test data processing algorithms and various parsing techniques which could introduce uncertainties in the individual phase properties derived. Hence the HEXRD-derived individual phase properties should only be used as references for comparison purpose rather than the "exact" solutions. The similar results between HEXRD and nanoindentation as shown in Fig. 9 serve as a verification that the inverse methodology based on nanoindentation load-depth curves can be an alternative way in determining individual phase properties. 
On the other hand, micropillar compression tests have also been reported as a direct measurement technique in obtaining the micromechanical properties of individual phases in multi-phase steels [38, 43, 53]. For example, Ghassemi-Armaki et al. [43] used uniaxial compression of focused ion beam-milled cylindrical micropillars to assess the mechanical properties of ferrite and martensite in a dual phase steel. Various degrees of hardening are observed for the ferrite and martensite phases tested, and the authors acknowledge that while a single martensite block may exhibit elastic-perfectly plastic behavior, the presence of boundaries in the form of blocks and packets may lead to significant hardening. While the micropillar test is a direct measurement technique for individual phases, it is not suitable to measure the statistically represented individual phase stress-strain behaviors for an ensemble of grains due to the sophisticated and time-consuming process of sample preparation, grain size requirement, as well as the absence of potential strengthening mechanisms such as grain boundaries.

Compared to the above two techniques, nanoindentation offers the advantages of a surface-based measurement in providing the statistically representative local property variations within the meso-scale measurement region (around $40 \times 40 \mu \mathrm{m}^{2}$ ) covering hundreds of grains. In addition, nanoindentation is a widespread characterization technique with equipment available at most materials research institutions. Hence inverse method with instrumented nanoindentation tests should be a practical way in extracting phase properties for multiple phase materials.

Also, in previous research on DP steel or medium Mn steel [20,41, 42], the phase properties could be easily identified by either hardness or indentation locations, due to large grain or feature sizes. However, because of the complex microstructures (i.e., needle-like structure in $\mathrm{A} / \mathrm{TM}$ ) and rather small grain size in the current Q\&P sample, SEM images and 
statistical analysis with proper assumptions are needed to convert region properties to phase properties.

\subsection{Interface/grain boundary effect}

Interface (i.e., grain boundary) effect has been reported by several previous nanoindentation studies and there could be significant hardness variations for indentations near the grain boundaries [40, 43, 74-79]. As illustrated in Fig. 3, the indents in TM and A/UT are divided to two groups: one group near interface (NI) includes indentations within 1.5 indent diameters from the interface; and the other group near center $(\mathrm{CN})$ includes indents at the center of each grain [42]. The average hardness values of each group in austenite, tempered martensite and untempered martensite phases are listed in Table 2. Note that, in Table 2, the data for austenite came from 25 indents which have hardness smaller than $6 \mathrm{GPa}$ in A/UT and the data for untempered martensite came from the rest 61 indents in A/UT with hardness larger than 6 GPa.

From this table, it is observed that in TM, single martensite phase region, the average hardness of NI is higher than those of $\mathrm{CN}$. To further clarify this observation, two large TM grains (gain size $>2 \mu \mathrm{m}$ ) are highlighted in Fig. 3 and each indentation location as well as its hardness are presented in Fig. 10. In Fig. 10(a), the orange dashed lines represent the grain boundary and the distance from indentation to grain boundary was measured. The hardness of each indentation within this grain is shown in Fig. 10(b). Similarly, the grain boundary, indentation locations and hardness of another TM grain are shown in Fig. 10(c) and (d). Then the relationship between distance to grain boundary $(d)$ and hardness $(H)$ is plotted in Fig. 10(e). Fig. 10(e) clearly demonstrates that indentation hardness in general decreases with increasing distance from the grain boundary in tempered martensite. This phenomenon could be explained 
by several effects: higher geometrically necessary dislocations density near the grain boundary [40], grain boundary strengthening [76] or carbon diffusion from martensite to retained austenite during the partitioning process [80]. Higher carbon content resulted form diffusion can potentially lead to a high yield strength gradient for the martensitic islands. In addition, some researchers suggest that the influence of carbon content on yield stress is significant compared to martensite grain size effect [81].

Austenite and untempered martensite are mixed in the A/UT and the grain size of this region is much smaller than TM so that multi-indentation tests on single austenite or untempered martensite grain are not practical on the current Q\&P steel. Although variation has also been observed in Table 2 for hardness values of NI and $\mathrm{CN}$, further study is required to verify the relationship between hardness and indentation location.

\section{Conclusion}

In summary, a new inverse method was proposed to calculate the individual stress-strain curves from the nanoindentation load-depth curves. To ensure solution uniqueness, a power law hardening behavior was assumed, and an empirical relationship between yield strength and nanohardness was utilized. Modification has been introduced to consider indentation size effect, indenter bluntness and non-ideal geometry effect so the stress-strain curves from each indentation was estimated. A Q\&P steel with complex microstructures was used as an illustrative example in the development and verification of the proposed method. With SEM images and statistical analysis of the hardness histogram, each indentation and its corresponding phase were identified. The average stress-strain curves of each phase were calculated with the new inverse method and compared with those from HEXRD with reasonable agreement. In the current inverse method, the yield strength-nanohardness relationship can significantly influence the 
predicted hardening behavior of each phase. It is demonstrated that nanoindentation with the proposed inverse method can be a viable way in determining the individual phase properties in a complex multi-phase material with sub-micron microstructural features.

\section{Acknowledgements}

Pacific Northwest National Laboratory (PNNL) is operated by Battelle Memorial Institute for the US Department of Energy (DOE) under Contract No. DE-AC05-76RL01830. This work was funded by the DOE's Vehicle Technologies Office under the Automotive Lightweight Materials Program managed by Dr. William Joost. The helps of Mr. Mark Taylor in the Advanced Steel Processing and Products Research Center at the Colorado School of Mines for the nanoindentation tests are greatly appreciated.

\section{References}

[1] D. Tabor, Rev. Phys. Technol. 1 (1970) 145-179.

[2] D. Tabor, in: P.J. Blau, B.R. Lawn (Eds.), Microindentation Techniques in Materials Science and Engineering, ASTM International, Philadelphia, 1986, pp. 129-159.

[3] W.C. Oliver, G.M. Pharr, J. Mater. Res. 7 (1992) 1564-1583.

[4] W.C. Oliver, G.M. Pharr, J. Mater. Res. 19 (2004) 3-20.

[5] T.A. Venkatesh, K.J. Van Vliet, A.E. Giannakopoulos, S. Suresh, Scr. Mater. 42 (2000) 833839.

[6] A.E. Giannakopoulos, S. Suresh, Scr. Mater. 40 (1999) 1191-1198.

[7] Y.-T. Cheng, C.-M. Cheng, Appl. Phys. Lett. 73 (1999) 614-616.

[8] W.D. Nix, H. Gao, J. Mech. Phys. Solids 46 (1998) 411-425.

[9] H. Nili, K. Kalantar-zadeh, M. Bhaskaran, S. Sriram, Prog. Mater. Sci. 58 (2013) 1-29.

[10] H. Nili, G. Cheng, T.A. Venkatesh, S. Sriram, M. Bhaskaran, Mater. Lett. 90 (2013) 148151.

[11] S.P. Baker, W.D. Nix, J. Mater. Res. 9 (1994) 3131-3144.

[12] M. Dao, N. Chollacoop, K.J. Van Vliet, T.A. Venkatesh, S. Suresh, Acta Mater. 49 (2001) 3899-3918.

[13] Y.P. Cao, X.Q. Qian, J. Lu, J. Mater. Res. 21 (2006) 215-224.

[14] M. Zhao, N. Ogasawara, N. Chiba, X. Chen, Acta Mater. 54 (2006) 23-32.

[15] Z.-H. Xu, D. Rowcliffe, Philos. Mag. A 82 (2002) 1893-1901.

[16] N. Ogasawara, N. Chiba, X. Chen, Scr. Mater. 54 (2006) 65-70.

[17] J.M. Antunes, J.V. Fernandes, L.F. Menezes, B.M. Chaparro, Acta Mater. 55 (2007) 69-81.

[18] L. Wang, S.I. Rokhlin, J. Mater. Res. 21 (2006) 995-1011. 
[19] Y.P. Cao, J. Lu, Acta Mater. 52 (2004) 4023-4032.

[20] M.-Y. Seok, Y.-J. Kim, I.-C. Choi, Y. Zhao, J.-i. Jang, Int. J. Plast. 59 (2014) 108-118.

[21] J.H. Lee, T. Kim, H. Lee, Int. J. Solids Struct. 47 (2010) 647-664.

[22] N. Chollacoop, M. Dao, S. Suresh, Acta Mater. 51 (2003) 3713-3729.

[23] C. Heinrich, A.M. Waas, A.S. Wineman, Int. J. Solids Struct. 46 (2009) 364-376.

[24] T. Nakamura, Y. Gu, Mech. Mater. 39 (2007) 340-356.

[25] H. Lan, T.A. Venkatesh, Acta Mater. 55 (2007) 2025-2041.

[26] S. Shim, J.-i. Jang, G.M. Pharr, Acta Mater. 56 (2008) 3824-3832.

[27] I. Peyrot, P.-O. Bouchard, R. Ghisleni, J. Michler, J. Mater. Res. 24 (2009) 936-947.

[28] L. Wang, M. Ganor, S.I. Rokhlin, J. Mater. Res. 20 (2005) 987-1001.

[29] O. Casals, J. Alcala, Acta Mater. 53 (2005) 3545-3561.

[30] J.L. Bucaille, S. Stauss, E. Felder, J. Michler, Acta Mater. 51 (2003) 1663-1678.

[31] J.J. Kang, A.A. Becker, W. Sun, Int. J. Mech. Sci. 62 (2012) 34-46.

[32] T.S. Bhat, T.A. Venkatesh, Philos. Mag. 93 (2013) 4488-4518.

[33] G.M. Pharr, E.G. Herbert, Y. Gao, Annu. Rev. Mater. Res. 40 (2010) 271-292.

[34] A.C. Fischer-Cripps, Introduction to Contact Mechanics, 2nd ed., Springer US, New York, 2007.

[35] Y.-T. Cheng, C.-M. Cheng, J. Mater. Res. 14 (1999) 3493-3496.

[36] H. Lan, T.A. Venkatesh, Philos. Mag. 87 (2007) 4671-4729.

[37] Y. Zou, D. Goldbaum, J.A. Szpunar, S. Yue, Scr. Mater. 62 (2010) 395-398.

[38] P. Hosemann, J.G. Swadener, D. Kiener, G.S. Was, S.A. Maloy, N. Li, J. Nucl. Mater. 375 (2008) 135-143.

[39] H. Somekawa, C.A. Schuh, Scr. Mater. 68 (2013) 416-419.

[40] J. Kadkhodapour, S. Schmauder, D. Raabe, S. Ziaei-Rad, U. Weber, M. Calcagnotto, Acta Mater. 59 (2011) 4387-4394.

[41] B.B. He, M.X. Huang, Z.Y. Liang, A.H.W. Ngan, H.W. Luo, J. Shi, W.Q. Cao, H. Dong, Scr. Mater. 69 (2013) 215-218.

[42] M.D. Taylor, K.S. Choi, X. Sun, D.K. Matlock, C.E. Packard, L. Xu, F. Barlat, Mater. Sci. Eng. A 597 (2014) 431-439.

[43] H. Ghassemi-Armaki, R. Maaß, S.P. Bhat, S. Sriram, J.R. Greer, K.S. Kumar, Acta Mater. 62 (2014) 197-211.

[44] K. Miyahara, S. Matsuoka, T. Hayashi, Metall. Mater. Trans. A 32 (2001) 761-768.

[45] Q. Furnémont, M. Kempf, P.J. Jacques, M. Göken, F. Delannay, Mater. Sci. Eng. A 328 (2002) 26-32.

[46] E. De Moor, J.G. Speer, D.K. Matlock, J.-H. Kwak, S.-B. Lee, ISIJ Int. 51 (2011) 137-144.

[47] K.S. Choi, A. Soulami, W.N. Liu, X. Sun, M.A. Khaleel, Comput. Mater. Sci. 50 (2010) 720-730.

[48] X. Sun, K.S. Choi, W.N. Liu, M.A. Khaleel, Int. J. Plast. 25 (2009) 1888-1909.

[49] E. De Moor, J.G. Speer, D.K. Matlock, J.-H. Kwak, S.-B. Lee, Steel Res. Int. 83 (2012) 322-327.

[50] J. Alkorta, J.M. Martínez-Esnaola, J.G. Sevillano, J. Mater. Res. 20 (2005) 432-437.

[51] R. Rodriguez, I. Gutierrez, Mater. Sci. Eng. A 361 (2003) 377-384.

[52] J.T. Busby, M.C. Hash, G.S. Was, J. Nucl. Mater. 336 (2005) 267-278.

[53] J.L. Stewart, L. Jiang, J.J. Williams, N. Chawla, Mater. Sci. Eng. A 534 (2012) 220-227.

[54] X.H. Hu, K.S. Choi, X. Sun, Y. Ren, Y.D. Wang, Metall. Mater. Trans. A (2015). 
[55] J.L. Bucaille, A. Rossoll, B. Moser, S. Stauss, J. Michler, Mater. Sci. Eng. A 369 (2004) 8292.

[56] ASTM International, Philadelphia 2007.

[57] S.A. Hackney, J.R. Bradley, T.D. Wood, I. Miskioglu, J. Mech. Behav. Mater. 21 (2013) 169-174.

[58] K. Durst, B. Backes, O. Franke, M. Göken, Acta Mater. 54 (2006) 2547-2555.

[59] S.A. Rodriguez, R.M. Souza, J. Alcalá, Philos. Mag. 91 (2011) 1409-1423.

[60] L. Qian, M. Li, Z. Zhou, H. Yang, X. Shi, Surf. Coat. Technol. 195 (2005) 264-271.

[61] S. Lee, S.-J. Lee, B.C. De Cooman, Scr. Mater. 65 (2011) 225-228.

[62] E. Jimenez-Melero, N.H. van Dijk, L. Zhao, J. Sietsma, S.E. Offerman, J.P. Wright, S. van der Zwaag, Scr. Mater. 56 (2007) 421-424.

[63] J.-i. Jang, M.J. Lance, S. Wen, T.Y. Tsui, G.M. Pharr, Acta Mater. 53 (2005) 1759-1770.

[64] G.B. Olson, M. Cohen, Metall. Trans. A 13 (1982) 1907-1914.

[65] S.A. Rodriguez, J. Alcala, R.M. Souza, J. Mater. Res. 27 (2012) 2148-2160.

[66] E. Harvey, L. Ladani, M. Weaver, Mech. Mater. 52 (2012) 1-11.

[67] W.G. Jiang, J.J. Su, X.Q. Feng, Eng. Fract. Mech. 75 (2008) 4965-4972.

[68] C. Walter, T. Antretter, R. Daniel, C. Mitterer, Surf. Coat. Technol. 202 (2007) 1103-1107.

[69] K.-D. Bouzakis, N. Michailidis, S. Hadjiyiannis, G. Skordaris, G. Erkens, Mater. Charact. 49 (2002) 149-156.

[70] M.K. Khan, S.V. Hainsworth, M.E. Fitzpatrick, L. Edwards, Comput. Mater. Sci. 49 (2010) 751-760.

[71] D. Torres-Torres, J. Muñoz-Saldaña, L.A. Gutierrez-Ladron-de Guevara, A. HurtadoMacías, M.V. Swain, Modell. Simul. Mater. Sci. Eng. 18 (2010) 075006.

[72] G. Cheng, S. Sriram, M. Bhaskaran, T.A. Venkatesh, Appl. Phys. Lett. 105 (2014) 122902.

[73] G. Cheng, T.A. Venkatesh, Philos. Mag. Lett. 92 (2012) 278-287.

[74] B. Yang, H. Vehoff, Acta Mater. 55 (2007) 849-856.

[75] T. Eliash, M. Kazakevich, V.N. Semenov, E. Rabkin, Acta Mater. 56 (2008) 5640-5652.

[76] J. Lian, J.E. Garay, J. Wang, Scr. Mater. 56 (2007) 1095-1098.

[77] S. Pathak, J. Michler, K. Wasmer, S.R. Kalidindi, J. Mater. Sci. 47 (2012) 815-823.

[78] H. Somekawa, T. Mukai, Philos. Mag. Lett. 90 (2010) 883-890.

[79] W.A. Soer, J.T.M. De Hosson, Mater. Lett. 59 (2005) 3192-3195.

[80] D. Edmonds, D.K. Matlock, J.G. Speer, in: Y. Weng, H. Dong, Y. Gan (Eds.) Advanced Steels, Springer, Berlin 2011, pp. 241-253.

[81] M. Delincé, Y. Bréchet, J.D. Embury, M.G.D. Geers, P.J. Jacques, T. Pardoen, Acta Mater. 55 (2007) 2337-2350. 


\section{Tables}

Table 1 Phase volume fraction (PVF) of austenite, tempered martensite and untempered martensite from HEXRD and nanoindentation.

\begin{tabular}{cccc}
\hline Phase & $\begin{array}{c}\text { PVF from } \\
\text { HEXRD }\end{array}$ & Number of indentations & $\begin{array}{c}\text { PVF from } \\
\text { Nanoindentation }\end{array}$ \\
\hline Austenite & $13 \%$ & 25 from A/UT & $13 \%(52)$ \\
Untempered & $18 \%$ & 61 from A/UT & $15 \%(61)$ \\
martensite & & 112 from TM & \\
Tempered & $69 \%$ & 175 from A/TM & $72 \%(287)$ \\
martensite & & & \\
\hline
\end{tabular}

Table 2 Average hardness of austenite (A), tempered martensite (TM) and untempered martensite (UT) near interface or center.

\begin{tabular}{cccc}
\hline & $\begin{array}{c}\text { Average hardness } \\
\text { At Center (GPa) }\end{array}$ & $\begin{array}{c}\text { Average hardness } \\
\text { Near Interface (GPa) }\end{array}$ & $\begin{array}{c}\text { Average hardness } \\
\text { Overall (GPa) }\end{array}$ \\
\hline A & 5.42 & 5.52 & 5.50 \\
TM & 5.72 & 6.06 & 5.82 \\
UT & 7.34 & 7.12 & 7.14 \\
\hline
\end{tabular}




\section{Figures}

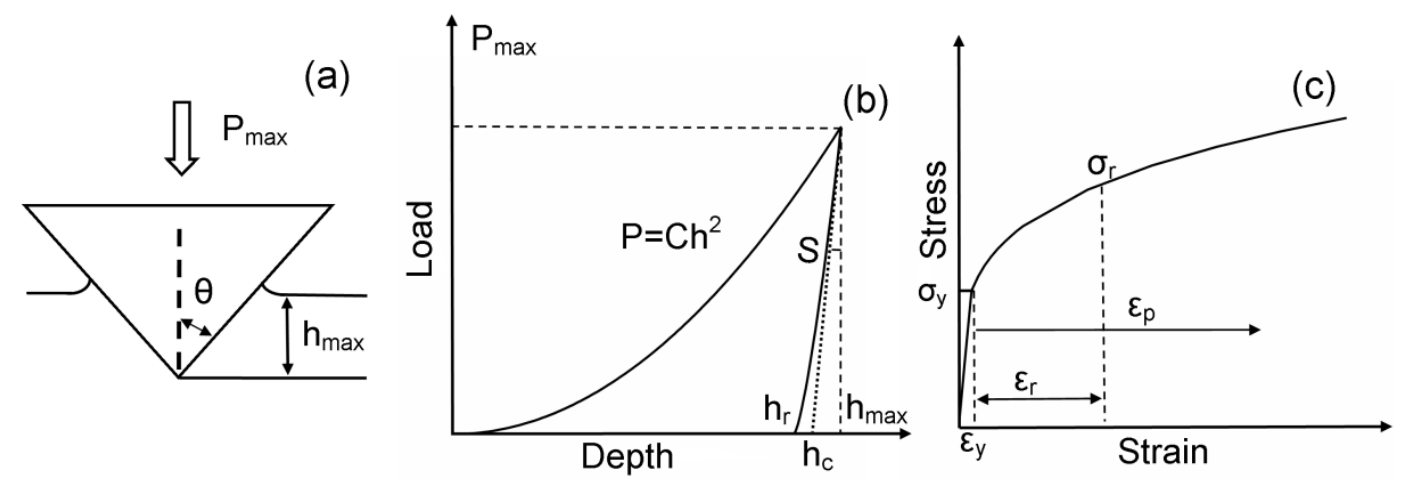

Fig. 1. Schematics of: (a) Berkovich indentation with pile-up effect, (b) load-depth $(P$ - $h)$ curves from indentation response of homogenous isotropic material and (c) power law elasto-plastic behavior of the indented material. 

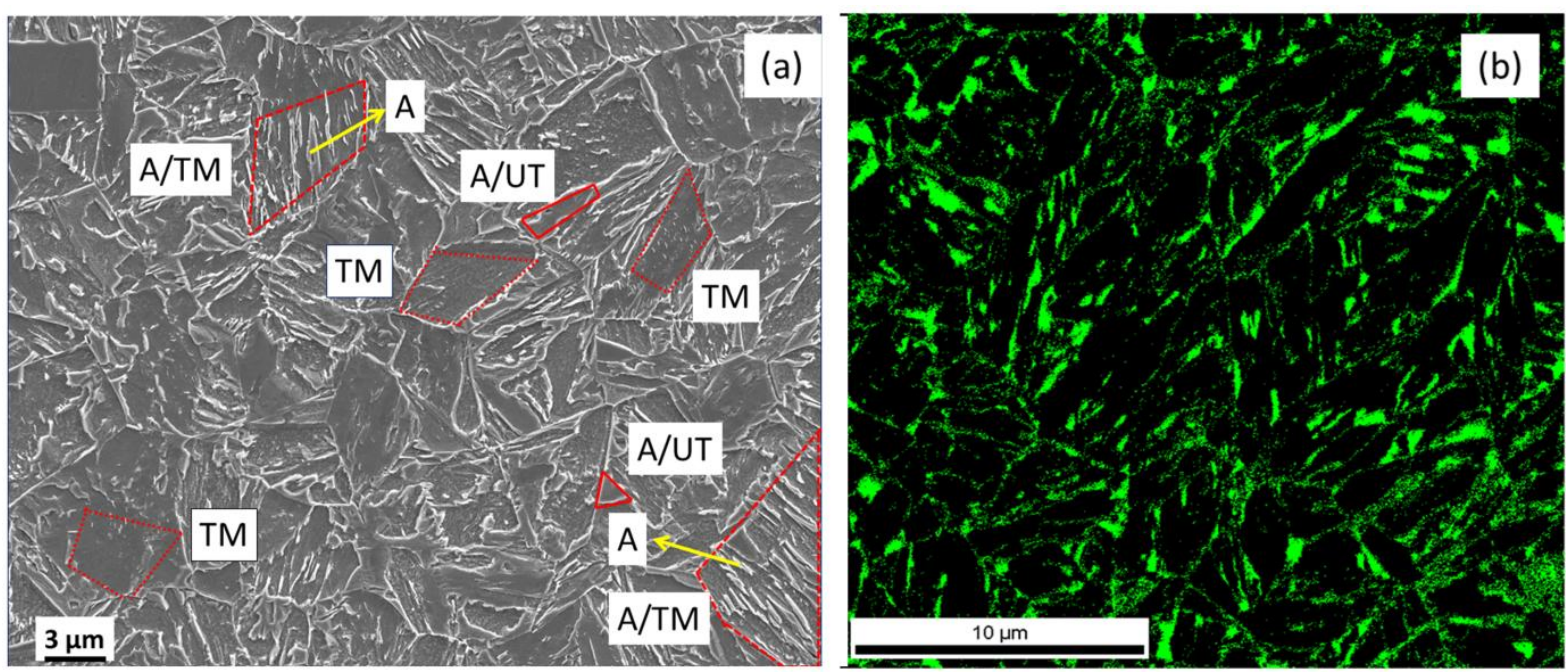

Fig. 2. (a) SEM micrograph of the $\mathrm{Q} \& \mathrm{P}$ steel (A, TM, A/UT and $\mathrm{A} / \mathrm{TM}$ represent austenite, tempered martensite, mixture of austenite and untempered martensite and mixture of austenite and tempered martensite, respectively) and (b) EBSD raw phase image of austenite. 


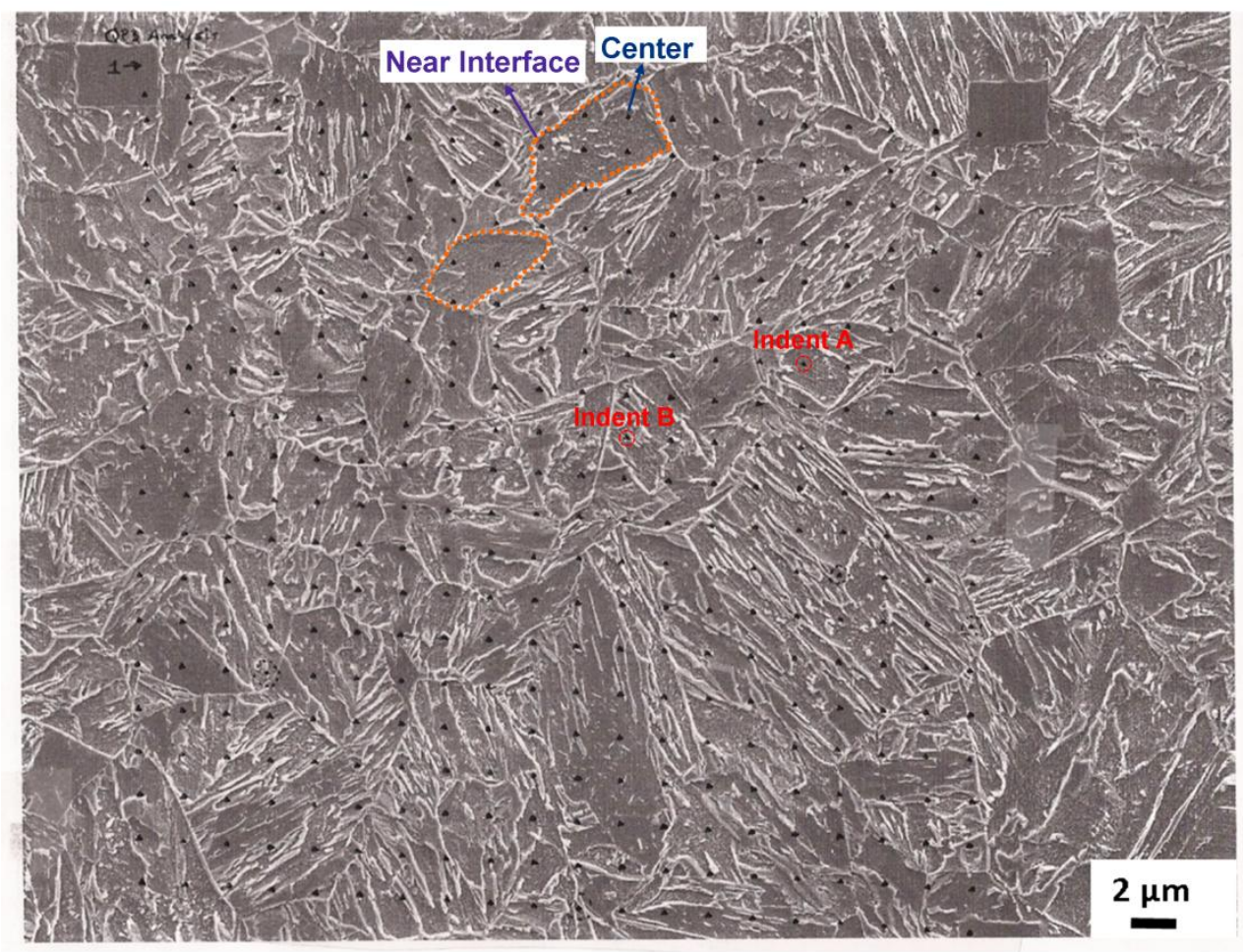

Fig. 3. Overlay of indentation locations on SEM image of the etched Q\&P steel: two tempered martensite grains (in orange dotted lines) and two indentations (red circles) marked with Indent $\mathrm{A} / \mathrm{B}$ 


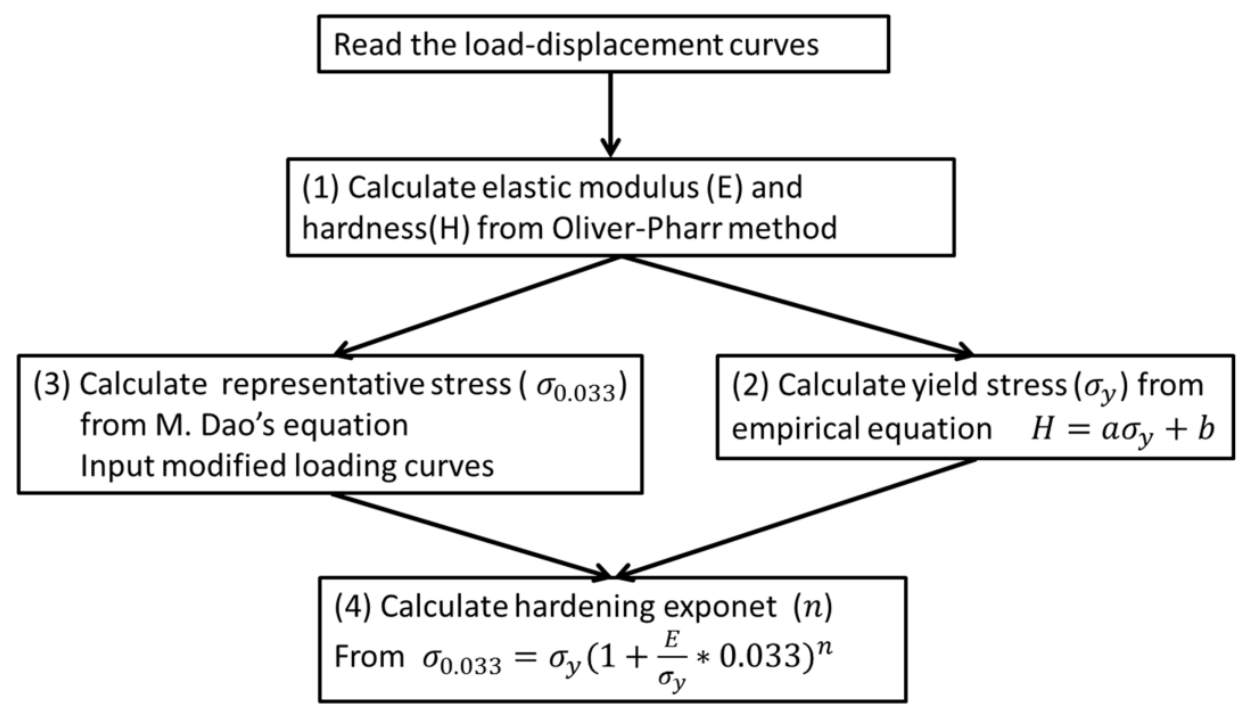

Fig. 4. Algorithms of inverse calculation to estimate the elasto-plastic properties from indentation load-depth curve. 

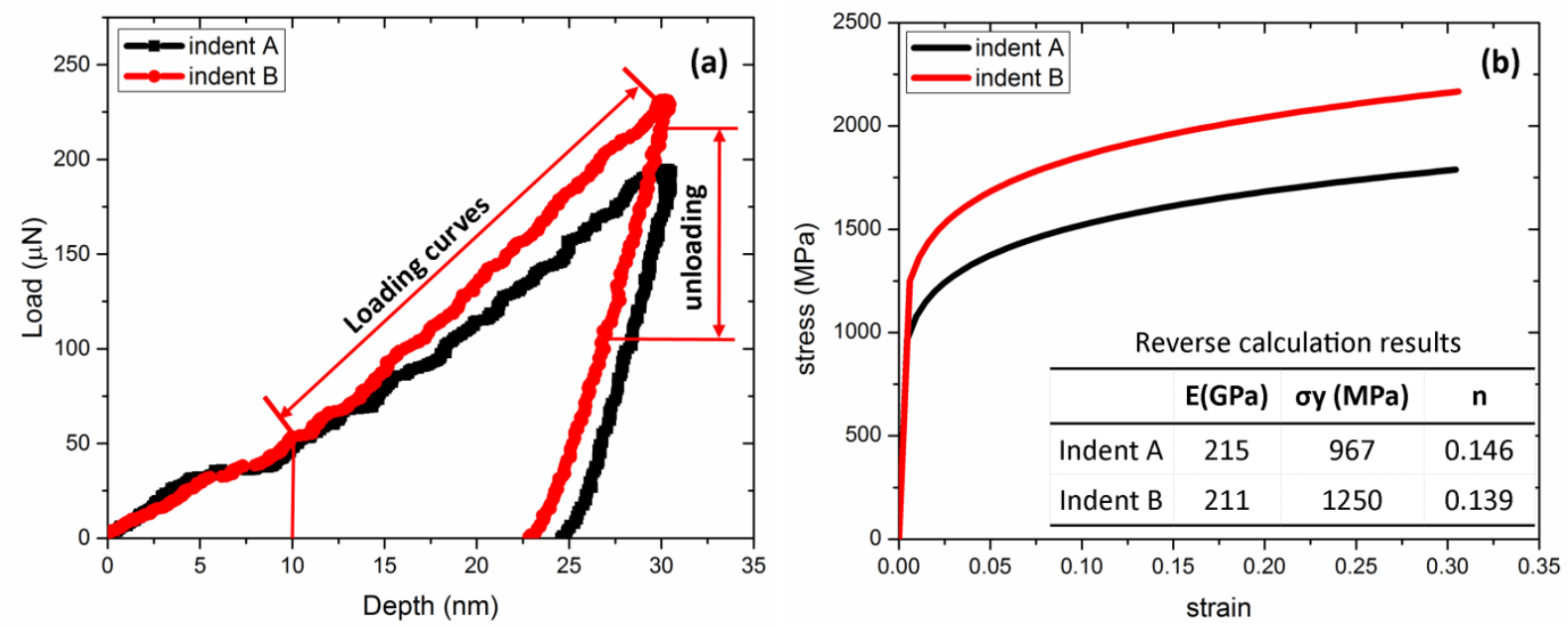

Fig. 5. Examples of inverse calculation from load-depth curves to stress-strain curves: (a) the original load-depth curves and (b) the stress-strain curves based on parameters calculated from the proposed inverse method. (Locations of two indentations were highlighted in Fig. 3) 

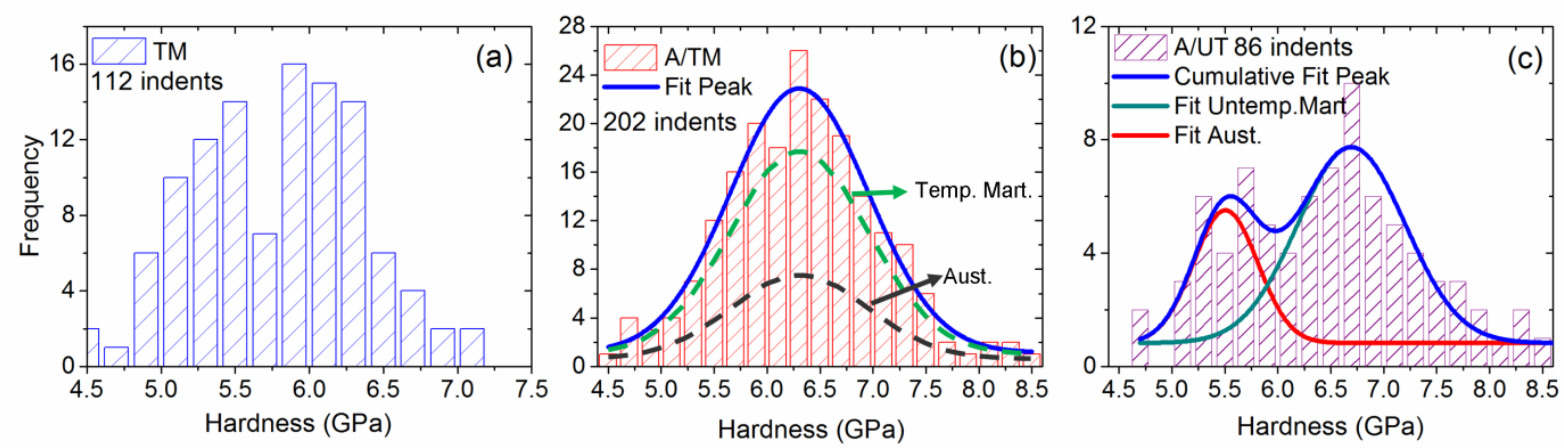

Fig. 6. Histogram of hardness and indentation frequency in different constituents: (a) tempered martensite (TM), (b) mixture of austenite and tempered martensite (A/TM): the cumulative fit of all indentations in this constituent (blue solid curve), assumed tempered martensite (green dashed curve) and austenite (black dashed curve) and (c) mixture of austenite and tempered martensite (A/UT): cumulative fit of all indentations in this constituent (blue solid curve), fitted distribution for untempered martensite (green solid curve) and fitted distribution for austenite (red solid curve). 

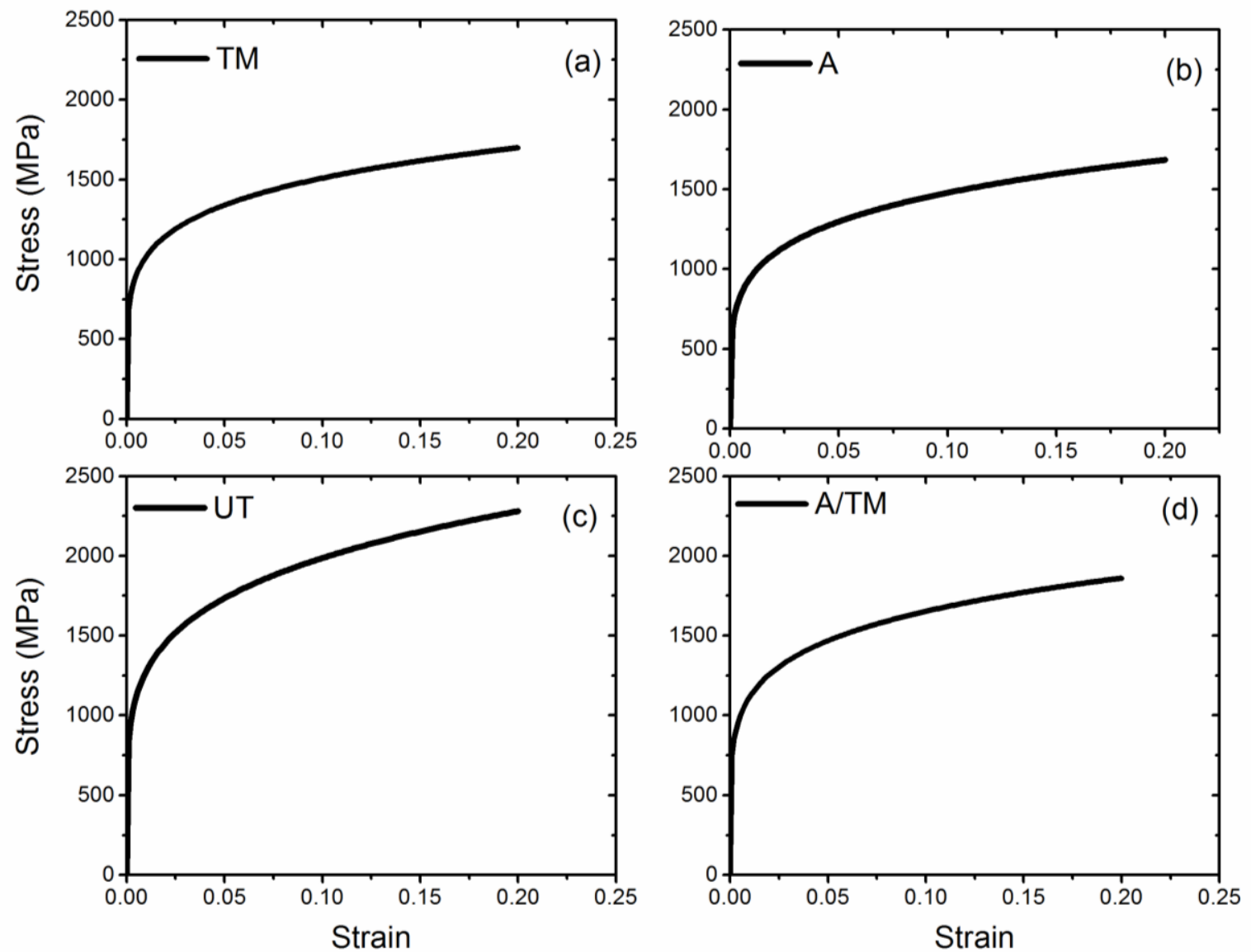

Fig. 7. Average stress-strain properties from inverse calculation for four different regions: (a) tempered martensite, (b) austenite from A/UT, (c) untempered martensite from A/UT and (d) A/TM. 

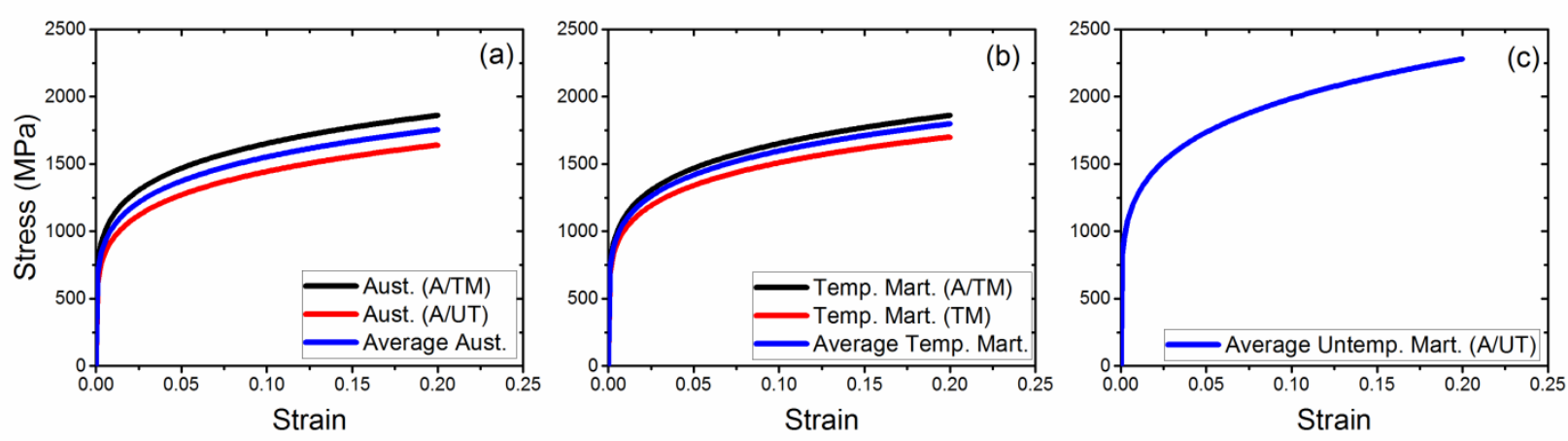

Fig. 8. The flow stress of each phase: (a) austenite, derived from austenite from A/TM (in black) and A/UT (in red) through Eq. (15), (b) tempered martensite, derived from tempered martensite from A/TM (in black) and TM (in red) through Eq. (16) and (c) untempered martensite. Note that the black curves in (a) and (b), the red curve in (a) and the red curve in (b) are the same as those in Fig. 7(d), Fig. 7(b) and Fig. 7(a), respectively. 

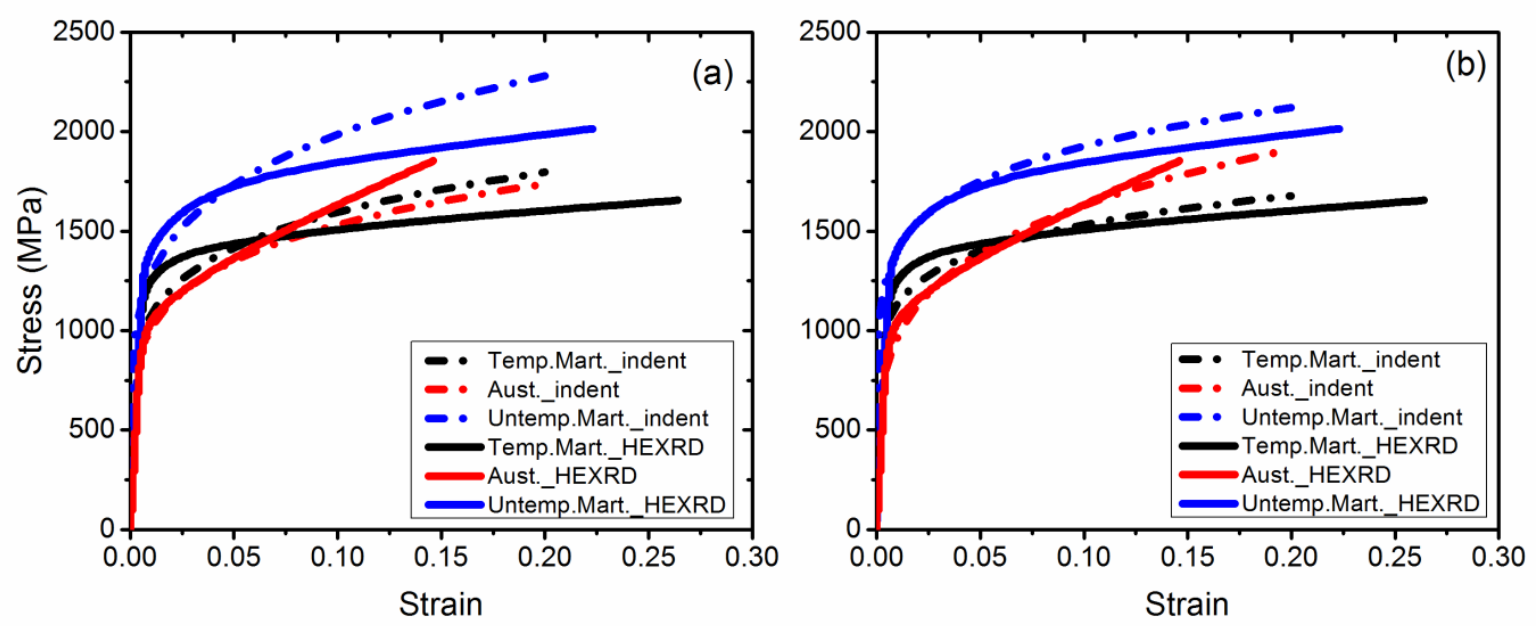

Fig. 9. Comparison of phase stress-strain curves from nanoindentation and HEXRD [54]: (a) $a=5.3$ and $b=1.3 \mathrm{GPa}$ for all three phases in Q\&P steel and (b) $a=5.3$ and $b=0.8 \mathrm{GPa}$ for tempered and untempered martensite, and $a=5.3$ and $b=1.8 \mathrm{GPa}$ for austenite. 

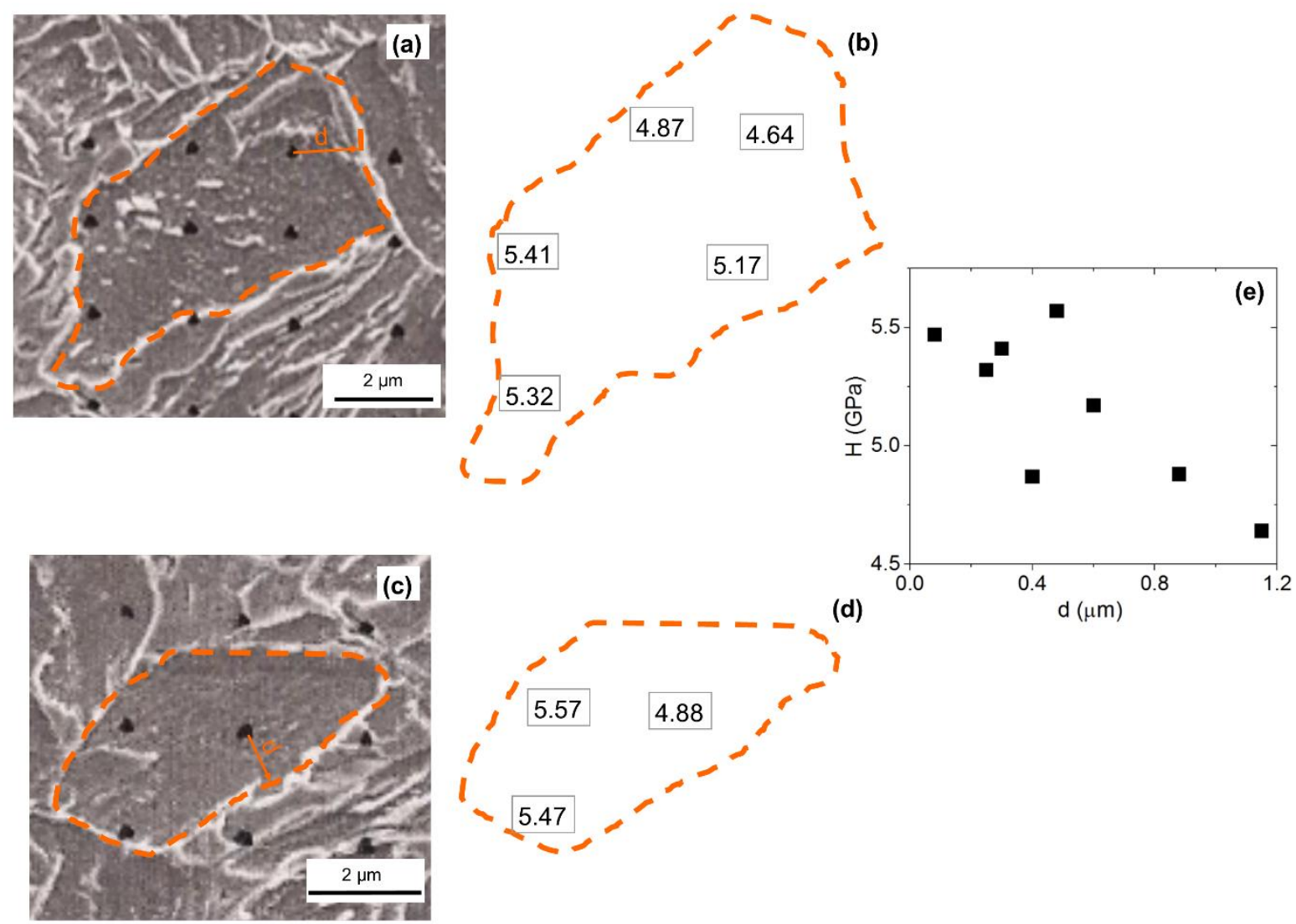

Fig. 10. Illustration of indentation locations and corresponding hardness in large tempered martensite grains: (a) and (c) SEM images of indentation locations (with the distance from an indentation to the closest grain boundary marked as $d$ ) and geometry shape of single grain (in orange dashed lines), (b) and (d) the corresponding hardness of single indentation shown in (a) and (c), and (e) the plot of distance to grain boundary $(d, \mu \mathrm{m})$ versus hardness $(H, \mathrm{GPa})$. 